\title{
O PARLAMENTARISMO COMO SISTEMA DE GOVERNO BRASILEIRO
}

Luís Henrique Ramos Alves, Shirley Oliveira Lima Nomura

Universidade do Oeste Paulista - UNOESTE, curso de Direito, Presidente Prudente, SP. E-mail:

luishenrique981@hotmail.com

\section{RESUMO}

O objetivo deste artigo científico é dizer sobre o Parlamentarismo - sistema de governo conhecido em ordem internacional - seu contexto histórico e suas características, com maior aprofundamento em relação ao território brasileiro, seu surgimento em âmbito nacional, os principais personagens deste marco e a sua aplicabilidade, com uma análise se o sistema parlamentarista corresponde aos anseios da sociedade atual, e se o sistema presidencialista ainda funciona de maneira moralmente aceita dentro do país. Os resultados foram que o sistema presidencialista vem passando por uma turbulência dentro do país, e com o estudo realizado sobre o Parlamentarismo é possível concluir que este pode ser uma opção de sistema que tente solucionar e que possa até mesmo resolver a atual crise que o pais está vivendo e enfrentando.

Palavras Chaves: Parlamentarismo, Regime Representativo, Chefe de Governo, Chefe de Estado, Crise Política.

\section{PARLIAMENTARIANS AS A SYSTEM OF BRAZILIAN GOVERNMENT}

\section{ABSTRACT}

This scientific article objective is to discuss about parliamentarism - governmental system known internationally - its historical context and its characteristics, with a bigger deepening about the brazilian territory, its beginning in a national ambit, this mark main characters and its applicability, analyzing if the parliamentary system still works in a morally acceptable way inside the country. The results were that the presidentialism system have been going through a turbulence inside the country, and by the study made about Parliamentary system it is possible to conclude that it can be a system option that could try to resolve and that could even end the current crises that the country has been experiencing and fighting against.

Keywords. Parliamentarism, Regime Representative, Head of government, Head of state, Political Crisis.

\section{INTRODUÇÃO}

Diante dos grandes escândalos que vem surgindo dentro do governo e dentro da política, é possível de se ver que o Brasil vem passando por uma crise institucional profunda, razão pela qual surge o questionamento, seria melhor para o país o sistema de governo Parlamentarista?

O Parlamentarismo atualmente é utilizado como sistema de governo por grandes países como Inglaterra, Canadá, Alemanha e Itália; E porque não o Brasil aderir esse sistema para tentar resolver a crise política. O presente artigo trará uma análise sobre a crise política que o Brasil está passando e como proposta para a resolução dessa crise ser trocado o sistema de governo presidencialista para o sistema de governo parlamentarista.

\section{ASPECTO HISTÓRICO: SURGIMENTO DO SISTEMA PARLAMENTARISMO E SUA EXPANSÃO}


O surgimento do Parlamentarismo é algo de grande repercussão dentre os estudos realizados pelos doutos da disciplina de Teoria Geral do Estado e deve ganhar uma maior atenção.

O Sistema Parlamentarista possui suas raízes na Inglaterra Medieval. No fim do século XIII, ilustres ingleses queriam uma maior participação política no governo, dessa forma começaram a atacar os privilégios e as prerrogativas do rei com o objetivo de que este se enfraquecesse e perdesse o seu poder absoluto e através disso viesse a assinar a carta magna, que impunha o dever de respeitar os cidadãos e percorrer ao parlamento quando desejasse elevar os impostos.

A Inglaterra pode ser considerada o berço do governo representativo. Já no século XIII, o mesmo que assistiu à elaboração da Magna Carta, numa rebelião dos barões e do clero contra o monarca, iria ganhar forma de parlamento. No ano de 1265 um nobre francês, Simon de Montfort, neto de inglesa e grande amigo de barões e eclesiásticos ingleses, chefiou uma revolta contra o rei da Inglaterra, Henrique III, promovendo uma reunião que muitos apontam como a verdadeira criação do parlamento. (DALLARI, 2016, p. 228).

Como vimos, a Inglaterra é classificada como o local de nascimento deste sistema, é possível dizer que a principal prerrogativa destes era quebrar com o poder absoluto das monarquias absolutistas.

Segundo Dallari, a estopim do parlamentarismo surgiu no ano de 1213, onde, o "próprio João Sem Terra convocará 'quatro cavaleiros discretos' de cada condado, para com eles 'conversar sobre os assuntos do reino'”. (DALLARI, 2016, p. 228). Mas somente no fim do século XVIII, através de grandes lutas políticas, religiosas e familiares, iniciaria enfim a criação do parlamento.

No século XVII, insatisfeito com a falta de poder que antes possuía, Jaime II procura tomar o poder do parlamento para a monarquia, mas não obtém resultado. O Parlamento e o parlamentarismo se estabilizam na Declaração de Direitos dos Estados Unidos (Bill of Rights), o que enfraquece de vez a monarquia, não tendo mais o poder absoluto para governar, passa a cortejar a maioria do parlamento com a finalidade de ter uma possibilidade de vim a governar. A partir das conferências entre o rei e os líderes influentes da maioria do parlamento formaram o conselho, que originou o gabinete como é conhecido no sistema parlamentarista.

O Parlamentarismo se fez de suma importância, no que tange a Declaração de Direitos Dos Cidadãos. Paulo Bonavides afirma que com a: "Bill of Rights se tem o verdadeiro documento constitucional que afiança as liberdades públicas, as liberdades de opinião de ação política e consciência" (BONAVIDES, 1995, p. 237).

Com a implementação do parlamentarismo na Inglaterra, outros países foram influenciados, espalhando-se de forma rápida por toda a Europa.

Bélgica, Prússia, Alemanha, Polônia, Checoslováquia, Áustria, Grécia, lugoslávia, Finlândia, Espanha e outros, passa o sistema por várias adaptações exigidas pelas peculiaridades locais, sem perder, contudo, as características fundamentais do modelo Britânico. (MALUF, 2013, p. 292)

Exemplo disso é a França que "empolgou-se com as maravilhas do sistema inglês e passou a adaptá-lo às suas instituições, por meio de reformas parciais desde a primeira metade do século XIX" (MALUF, 2013, p. 291).

Há três tipos de parlamentarismo o Clássico, Racionalizado e o Misto. O principal é, o Clássico que foi "construído na Inglaterra durante o século XVII" (SOARES, 2001, p. 511). O 
Parlamentarismo racionalizado decorre "das constituições formuladas, após a Primeira Guerra" (SOARES, 2001, p. 512). Por fim, o Parlamentarismo Misto deriva-se da "racionalização de outros setores do sistema parlamentar, cristalizando-se nas modalidades de tendência diretorial, presidencialista e de equilíbrio" (SOARES, 2001, p. 512).

\section{CARACTERÍSTICAS DO SISTEMA PARLAMENTARISTA}

Veremos agora as principais características do sistema parlamentarista de governo de acordo com Dalmo de Abreu DALLARI.

a) Diferença entre Chefe de Estado e Chefe de Governo: No sistema Parlamentarista há uma diferença entre chefe de Estado e chefe de Governo, essas duas funções são exercidas por pessoas diferentes. $O$ chefe de Estado é exercido pelo monarca este é o maior representante público de um Estado, normalmente seu papel é garantir a legitimidade do Estado e o exercício de poderes, funções e deveres atribuídos ao chefe de Estado pela Constituição do país, além disso desempenha um papel de grande relevância nos momentos de crise, quando é necessário indicar um 10 Ministro à aprovação do Parlamento. O chefe de Governo dentro do sistema parlamentarista exerce a função de chefe do executivo. Como já foi dito ele é indicado pelo chefe de Estado que só passa a ser 10 Ministro após à aprovação do Parlamento.

b) Chefe do Governo com Responsabilidade Política: O Chefe de Governo dentro do Parlamentarismo depois de aprovado pelo Parlamento não possui mandato com tempo certo de duração pode durar de 1 dia a muitos anos. Foi criada a praxe de se escolher o Primeiro Ministro como um representante da maioria parlamentar. É condicionada a sua permanência no cargo à manutenção da maioria. Um parlamentar ao desaprovar a política do Primeiro Ministro, pode propor ao Parlamento um voto de desconfiança. Se aprovado, o Primeiro Ministro deve demitir-se.

c) Dissolução do Parlamento: Uma característica importantíssima desse sistema é a possibilidade de o parlamento ser dissolvido sendo extinto o mandato dos membros da Câmara dos Comuns antes do prazo normal. Há essa possibilidade quando o Primeiro Ministro constata que possui apenas uma reduzida maioria no Parlamento, ou quando o Primeiro Ministro recebe um voto de desconfiança mas compreende que na realidade quem se encontra fora do anseios da vontade popular é o próprio parlamento, diante disso ele pode solicitar ao Chefe de Estado que declare extintos os mandatos dos membros e convoque novas eleições gerais.

\section{PARLAMENTARISMO NO BRASIL}

No Brasil, o Parlamentarismo vigorou no final do império de 1847 a 1889 . É possível de se concluir também através do art. 75 da Constituição de 1937. São prerrogativas do Presidente da República: b) dissolver a Câmara dos Deputados no caso do parágrafo único do art. 167.

Quando o Brasil passou a ser República foi adotado o sistema presidencialista de governo, todavia quando Jânio Quadros renunciou seu mandato o país passou por uma grande crise política e o sistema parlamentarista passou a ser adotado novamente como uma opção para tentar solucionar a crise, no período de setembro de 1961 a janeiro de 1963. Diante dessa organização o governo passou a ser exercido por um corpo coletivo de pessoas. O Poder Legislativo responsabiliza-se, por exercer funções de maior proporção na administração do país, muda-se em Parlamento integrando também os membros do governo. Tudo passa a depender da confiança desse parlamento e do seu apoio para poder exercer seu cargo, se o Parlamento retirar a confiança no governo ele cai, pois não tem mandato, mas apenas investidura de confiança.

Após a promulgação da Constituição Federal de 1988 houve um plebiscito no dia 07 de setembro de 1993 para decidir entre sistema presidencialista de governo e sistema 
parlamentarista de governo e os cidadãos escolheram o sistema presidencialista, isto está registrado no art.2ㅇ do ADCT/CF 1988.

\section{A CRISE POLÍTICA ATUAL E A APLICAÇÃO DO SISTEMA PARLAMENTARISTA DENTRO DO GOVERNO BRASILEIRO.}

Nesses últimos anos o Brasil tem passado por uma crise institucional política muito grande, uma anormalidade na administração do país. É possível notar através das grandes manifestações que tem sido cada vez mais frequentes, o inconformismo do povo com o atual governo, com a instabilidade na economia, com a grande taxa de desemprego e com os grandes escândalos de corrupção, que passaram a serem vistos como algo corriqueiro, com envolvimento de parlamentares e até mesmo do Presidente da República, representantes que deveriam possuir conduta ilibada, servir a população e gerir o país para a ordem e o progresso. Diante de tudo isso surge o seguinte questionamento: será que o presidencialismo ainda funciona de forma eficaz e moralmente aceita dentro do país?

Atualmente estamos diante de uma grande crise de confiança nas instituições políticas, a população não tem mais acreditado no governo atual, e com isto nasce a desconfiança no governo e desaprovação pela sociedade. O que temos hoje não é um sistema presidencialista que busca governar o país de acordo com o anseios da sociedade mas sim um governo que quer alcançar e manter o poder político tendo ânsia pelo poder e pela manutenção de privilégios, que para conseguirem isso usam de todos os meios: alianças, articulações, corrupção, chantagem.

Diante disso a aplicação do sistema Parlamentarista dentro do governo brasileiro poderia trazer soluções para o problema da crise atual. Os cidadãos veria uma grande diferença no momento de votar, estes não votariam mais para um presidente pois este seria nomeado pelo Congresso Nacional e seria o Chefe de Governo, haveria uma nova figura na política nacional, que se tornaria mais importante que o próprio presidente do Poder Executivo que seria o Primeiro Ministro, os cidadãos elegeriam o Congresso e o Congresso elegeria o Primeiro Ministro. Com isso o Congresso ganharia mais destaque nos debates da política nacional, já que todas as decisões políticas estariam nesse poder, inclusive a escolha do primeiro ministro. Com o sistema Parlamentarista sendo o sistema de governo Brasileiro haveria vantagens, pois o sistema parlamentarista é mais flexível que o sistema presidencialista, diante de crises políticas e escândalos políticos podem ser solucionados com o voto de censura que é uma solução mais rápida pois o primeiro ministro pode ser trocado com urgência e pode haver a dissolução do parlamento, diferente do sistema presidencialista a qual o presidente cumpre o mandato mesmo passando por crise política. No sistema Parlamentarista há também uma facilidade e agilidade na aprovação das leis; uma maior comunicação entre o Executivo e o Legislativo, possibilitando uma maior e melhor transparência e fiscalização; diminuição dos custos das campanhas eleitorais o que no sistema presidencialista se gasta muito; menores chances de envolvimento em corrupção e escândalos políticos, pois o Parlamentar pensaria melhor antes de se envolver em coisas imorais por conta da diluição do poder e do voto de censura.

\section{CONCLUSÃO}

Portanto com o estudo realizado é possível ver que o Brasil além de estar passando por uma grande crise política está passando também por uma crise de confiança e reprovação que está afetando milhões de pessoas por má administração e por falta de conduta ilibada dos governantes e com isso é necessário a busca por uma solução para que estás crises não piore e que seja possível converter essa crise e o país voltar a crescer em todas áreas diante disso o artigo cientifico vem mostrar que o Sistema Parlamentarista de Governo que é utilizado em grandes 
países pode ser uma opção de sistema que tente solucionar ou até mesmo resolver a atual crise que o pais está vivendo, para que com essa resolução o país volte a crescer.

\section{REFERÊNCIAS BIBLIOGRÁFICAS}

DALLARI, Dalmo de Abreu. Elementos de Teoria Geral do Estado: 31. ed. São Paulo: Saraiva, 2012. MALUF, Sahid. Teoria Geral do Estado: 31. ed. São Paulo: Saraiva, 2014.

BONAVIDES, Paulo, Teoria Geral do Estado: 3‥ ed. São Paulo: Malheiros 1995.

PANCIARELLI, Antônio. Parlamentarismo e Presidencialismo: O que é melhor?. Disponível em: $<$ http://www.politize.com.br/parlamentarismo-e-presidencialismo-qual-o-melhor/>. Acesso em 20 de Maio de 2017.

BLUME, André Bruno. Sistemas de Governo: o Parlamentarismo. Disponível em: <http://www.politize.com.br/parlamentarismo-sistemas-de-governo/>. Acesso em 29 de Maio de 2017.

ARAÚJO, Ana Paula. Parlamentarismo. Disponível em: <http://www.infoescola.com/formas-degoverno/parlamentarismo/>. Acesso em 10 de Junho de 2017.

JUSBRASIL. Parlamentarismo $\mathrm{x}$ Presidencialismo. Disponível em: <https://gnipper.jusbrasil.com.br/artigos/377180518/parlamentarismo-x-presidencialismo>. Acesso em 15 de Junho de 2017.

EDUCAÇÃO. Diferenças entre Presidencialismo e Parlamentarismo. Disponível em: <http://www.educacao.cc/politica/diferencas-entre-presidencialismo-e-parlamentarismo/>. Acesso em 15 de Junho de 2017.

MARCIAL, Everaldo. Sobre a atual Crise Brasileira. Disponível em $<$ http://blogdapoliticabrasileira.com.br/sobre-atual-crise-brasileira/>. Acesso em 25 de Junho de 2017.

BOITO Jr. Armando. Parlamentarismo. Disponível em <http://www.suapesquisa.com/o_que_e/parlamentarismo.htm.> Acesso em 29 de Junho de 2017.

VALLE, Alberto. A atual situação econômica no Brasil. Disponível em <http://www.empreendedoresweb.com.br/atual-situacao-economica-do-brasil/.> Acesso em 29 de Junho de 2017. 